\title{
The role of microbiome in colorectal carcinogenesis and its clinical potential as a target for cancer treatment
}

\author{
Sang Hoon Kim, Yun Jeong Lim \\ Department of Internal Medicine, Dongguk University Ilsan Hospital, Dongguk University College of Medicine, Goyang, Korea
}

The role of gut microbiome-intestinal immune complex in the development of colorectal cancer and its progression is well recognized. Accordingly, certain microbial strains tend to colonize or vanish in patients with colorectal cancer. Probiotics, prebiotics, and synbiotics are expected to exhibit both anti-tumor effects and chemopreventive effects during cancer treatment through mechanisms such as xenometabolism, immune interactions, and altered eco-community. Microbial modulation can also be safely used to prevent complications during peri-operational periods of colorectal surgery. A deeper understanding of the role of intestinal microbiota as a target for colorectal cancer treatment will lead the way to a better prognosis for colorectal cancer patients. (Intest Res 2022;20:31-42)

Key Words: Intestinal microbiome; Probiotics; Prebiotics; Synbiotics; Colon neoplasms

\section{INTRODUCTION}

Colorectal cancer (CRC) is the second most common cancer in men and the third in women globally. It is also the second most commonly diagnosed cancer after gastric cancer in South Korea, with 30,000 new diagnoses and 8,700 deaths each year. ${ }^{2}$

There are many long-term and late effects during the treatment of CRC, including chronic peripheral neuropathy, secondary cancers, bowel dysfunction such as nausea and diarrhea, and psychological issues such as depression and anxiety. ${ }^{3}$ Most current guidelines focus on diagnosis and treatment of the tumor itself, but there is also a need for a "better adjunctive care" during the colon cancer treatment, and one of them is the "modulation of gut microbiota."

The human intestine is an organ inhabited by billions of microorganisms, of which $10^{14}$ are in the colon., These microorganisms are collectively referred to as "microbiota." Their genes

Received February 25, 2021. Revised April 18, 2021. Accepted April 23, 2021. Correspondence to Yun Jeong Lim, Department of Internal Medicine, Dongguk University Ilsan Hospital, 27 Dongguk-ro, Ilsandong-gu, Goyang 10326, Korea. Tel: +82-31-961-7133, Fax: +82-31-961-7730, E-mail:

drlimyj@gmail.com are called "microbiome" or "the 2nd genome" of humans. The importance of the gut microbiome in colorectal carcinogenesis is relatively well known. Active research is underway on the effects of microbial modulation through pre- and probiotics during cancer treatment.

This review is aimed to attract attention regarding the beneficial effects of intestinal microbial modulation during the treatment course of CRC. A deeper understanding of this topic will help the treatment of CRC patients. In the long term, it will help us develop tailored therapy according to characteristics of patient-specific intestinal microbiota and their immunologic states.

\section{GUT MICROBIOME-INTESTINAL IMMUNE COMPLEX}

"All disease begins in the gut." As mentioned in the 3rd century BC by Hippocrates, the gut microbiome plays surprisingly diverse roles. They contribute to the body's energy metabolism, synthesis of vitamins and other essential nutrients, signaling the endocrine system, preventing colonization of harmful bacteria, regulating the immune system, and contributing to the metabolism of xenobiotic compounds. ${ }^{6,7}$ 
Maintaining the intestinal mucosa's immunological homeostasis begins with a challenging task of discriminating rare pathogenic species from billions of harmless microbes. During this process, both innate and adaptive immune responses prevent colonization of pathogens and induce local and systemic inflammatory responses to foreign microbial and dietary antigens. Gut-associated lymphoid tissue is the backbone of immune surveillance and defense mechanism. It consists of Peyer's patch, appendix, isolated lymphoid follicle, and mesenteric lymph nodes. It is responsible for both activation and suppression of the mucosal immune system. The presence of intestinal bacteria is also essential for the development and maturation of the gut-associated lymphoid tissue. ${ }^{8}$

When pathogens or symbiotic bacteria cross the epithelial barrier and enter the host, they first encounter macrophages. Antigens that are not phagocytosed by macrophages are captured by intestinal dendritic cells and migrated from the intestine to mesenteric lymph nodes, triggering a differentiation process that leads to the production of regulatory T cells (Treg), T-helper 17 (Th17), and IgA secreting B-cells. ${ }^{9}$ According to a study using germ-free mice, the intestinal microbial community plays an important role in forming adequate mucosal immunity. Compared to specific pathogen-free mice, germ-free mice had fewer intraepithelial lymphocytes, less sIgA secretion in the lamina propria, and fewer Treg production. ${ }^{10}$

Foxp3+ Treg cells play a key role in intestinal immune tolerance mechanisms. ${ }^{11}$ CD4+Foxp3+ Treg cells derived from naive CD4+ T cells in both the thymus (nTreg) and intestine (iTreg) can help maintain immune unresponsiveness to autoantigens and suppress excessive immune reactions that might be harmful to the host. In an environment where Treg cells are abnormally present, proper immune tolerance is not induced, resulting in hypersensitive reactions. ${ }^{12,13}$ Bacteroides fragilis, a type of symbiotic bacteria, can produce polysaccharide A, inhibit interleukin17 (IL-17) production from Th17 cells, and enhance the activity of iTregs, leading to anti-inflammatory effects. polysaccharide A can also induce the transformation of CD4+ T cells into Foxp3+ Tregs. It can also down-regulate the production of pro-inflammatory Th17 cells. ${ }^{14,15} \mathrm{~B}$. fragilis is known to be able to improve colitis in a mouse model. However, Bacteroides spp. are thought to have ambivalence as $B$. fragilis toxin (BFT) can cause inflammatory bowel disease by altering the function of epithelial tight junctions. ${ }^{16,17}$

Th17 cells in the mucous membrane of the small intestine are vital in protecting the mucosal surface from microbial pathogens. However, they are also notorious for inducing autoim- mune inflammation when they are activated by IL-23. ${ }^{18,19} \mathrm{Th} 17$ cells seem to have an opposite function of Tregs. ${ }^{20-23}$ Recently, it has been reported that Th17 cells are a unique CD4+ T-helper subset characterized by the production of IL-17, which can promote inflammation against a variety of pathogens. Specific intestinal microflora that can induce small intestinal Th17 cells are known as "segmented filamentous bacteria."

Another role of intestinal microbes is that they can ferment polysaccharides (such as resistant starch, oligosaccharides, inulin, etc.) that humans cannot normally digest or absorb, resulting in the production of short-chain fatty acids (SCFA). ${ }^{26}$ These SCFAs also contribute to the activation of several types of immune cells and play an important role in the differentiation of Treg cells. ${ }^{27,28}$

As described above, it has been suggested that modulating the gut microbiome may prevent or worsen various types of inflammatory and allergic diseases because it can alter the differentiation of immunologic cells and modulate the production of SCFA by promoting colonization of beneficial bacteria. ${ }^{29,30}$

\section{MICROBIAL SIGNATURES OF CRC}

The gut microbiota has a large diversity of microbial populations composed of bacteria, archaea, eukaryotes, and viruses. Both tissue and fecal samples provide information on the structure of bacterial populations. Analyzing tissue samples will show a more direct relationship between colon cancer's pathophysiology and the gut microbiota. However, since sampling the intestinal mucosa is invasive, research using biopsy samples from normal mucosa is particularly limited. Therefore, most studies rely on fecal samples to analyze the distribution and diversity of intestinal microorganisms.

Most bacteria that reside in the gut are strictly anaerobic, and therefore they cannot be grown or cultured. The ability to identify bacteria using culture-independent methods was a huge advance in the microbiome field. Sequencing V1-V3 or V3-V5 variable regions of bacterial $16 \mathrm{~S}$ ribosomal RNA has become a standard method for identifying bacterial populations or operational taxonomic units known to generally represent bacterial species whose sequences share more than 97\% identities to each other. ${ }^{31}$ Using the 16s rRNA target gene sequencing method and the recently introduced shotgun metagenomic sequencing, we can obtain more detailed information on the intestinal microbiome.

The gut microbiota not only promotes intestinal homeosta- 
sis and anti-tumor responses, but also contributes to genotoxic effects that can lead to carcinogenesis by causing chronic dysregulated inflammation. ${ }^{32}$ Whether the gut microbiota will form a healthy symbiosis relationship with the host or promote colon cancer ultimately depends on the composition of gut microbiota and the balance between harmful bacterial populations within the microbiome. However, whether this "dysbio- sis" might precede or cause CRC remains unclear. Studies on mice strongly suggest that gut microbiota may modulate susceptibility to CRC and may serve as both early diagnostic biomarkers and therapeutic targets. Such clinical research should be done considering the influence of each individual's race, lifestyle, diet, sample type, location of the tissue sampled, and gut microbial ecosystem. Several notable shifts in the phylum
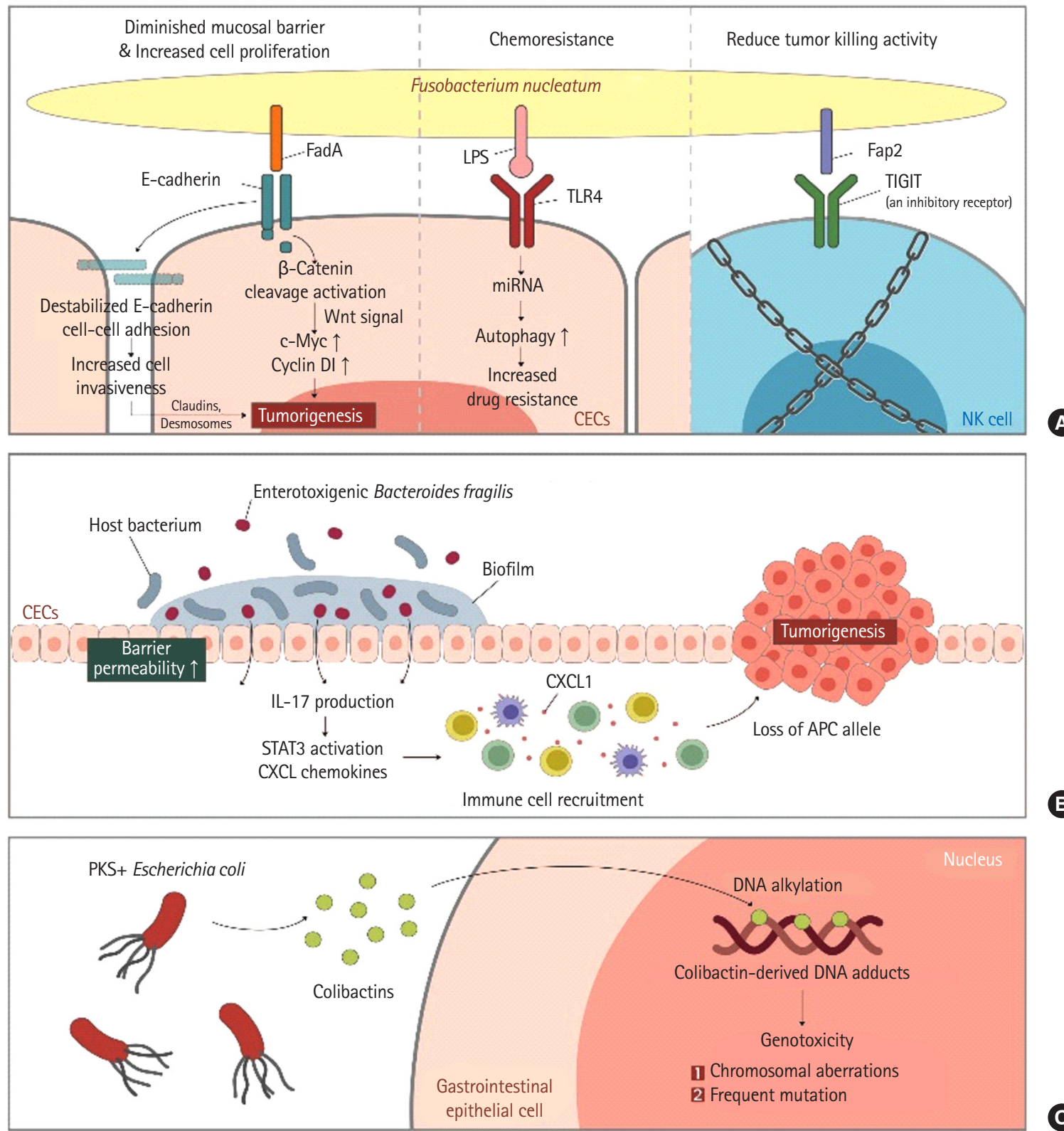

C

Fig. 1. Step-by-step mechanisms of microbiota inducing colorectal cancer. Proposed mechanisms by which commensal gut microbiota interact with gastrointestinal epithelium and induce colorectal cancer. (A) Fusobacterium nucleatum. (B) Enterotoxigenic Bacteroides fragilis. (C) PKS+Escherichia coli. LPS, lipopolysaccharide; TLR4, Toll-like receptor 4; TIGIT, T-cell immunoglobulin and ITIM domain; CEC, coIonic epithelial cell; NK cell, natural killer cell; IL, interleukin; STAT3, signal transducer and activator of transcription 3; CXCL, chemokine (C-X-C motif) ligand; CXCL1, chemokine (C-X-C motif) ligand 1 peptide; APC, adenomatosis polyposis coli; PKS, polyketide synthase. 
level have been reported in the intestinal bacterial community of CRC patients. Among them, Bacteroides, Fusobacteria, and Proteobacteria are increased while Firmicutes are decreased in both intestinal mucosa and feces of the colon cancer patients. ${ }^{33,34}$ More specifically, enterotoxic strains of B. fragilis and polyketide synthase (PKS) positive strains of Escherichia coli, Fusobacterium nucleatum are 3 most well-known strains in colorectal tumorigenesis (Fig. 1)..$^{35,36}$

Colonization of enterotoxin positive BFT (ETBF) has long been studied to be associated with diarrhea and gastrointestinal inflammation. ETBF also induced early carcinogenesis in mice models. ETBF coats tumors and recruits other bacteria to form a biofilm. Recently, increased colonization ETBF biofilms coating early human CRCs was confirmed. ${ }^{37} \mathrm{BFT}$ induces Th-17 mediated colitis and IL17-dependent carcinogenic inflammation through an accumulation of Treg cells.

E. coli species can be divided into 4 phylotypes (A, B1, B2, and D). Bonnet et al. ${ }^{38}$ and Raisch et al. ${ }^{39}$ confirmed that mucous membranes of cancer patients were much more abundant in E. coli subgroup B2. When B2 phylotype E. coli are incubated in vitro with various epithelial cell lines, they can arrest the epithelial cell cycle and force them to enter senescence. ${ }^{40-42}$ Such effect is due to a group of compounds collectively named cyclomodulins that can introduce double-strand DNA breaks in target cells. These cyclomodulins include cytolethal distending toxin, cytotoxic necrotizing factor, and the best known "colibactin" produced by the PKS locus. ${ }^{40,43,44}$ Colibactin is most likely a combination of hybrid molecules containing both a peptide and a polyketide produced in the gut by PKS positive E. coli. ${ }^{45}$ Transient infection of cultured epithelial cells with PKS positive E. coli can induce chromosomal aberrations and increase mutation frequency rates. Correspondingly, in animal models of carcinogenesis, exposure to PKS can induce DNA strand breaks and lead to tumor generation. ${ }^{36,46}$

While many independent studies have identified specific operational taxonomic units that can differentiate between healthy and CRC patients, F. nucleatum related to periodontal disease have gained attention due to their association with CRC. ${ }^{47,48}$ Its prevalence has been reported to be gradually increasing as the disease progresses from colon polyp to CRC. ${ }^{48}$ Studies in mice have shown that $F$ nucleatum can directly promote tumor growth. ${ }^{49}$ F. nucleatum can reduce natural killer cell-mediated tumor killing by interacting with receptor TIGIT (T-cell immunoglobulin and ITIM domain) and inhibiting anti-tumorous natural killer cell activity. ${ }^{50}$ In addition, E-cadherinmediated interactions with CRC epithelial cells can induce cell proliferation via Wnt signaling and avoid immune surveillance. ${ }^{51}$ Interestingly, there are reports that F. nucleatum is specifically related to microsatellite instability high tumors and that colonization of $F$. nucleatum is associated with relatively shorter cancer survival, ${ }^{51}$ making it suitable for use as a biomarker. Indeed, CRC with high loads of $F$. nucleatum, cells are more resistant to oxaliplatin by activating autophagy through Toll-like receptor 4 expressed on CRC cells. ${ }^{52}$ Fap2 and FadA of $F$. nucleatum are proteins facilitate the binding to TIGIT and E-cadherin and enriches tumor proliferation. They could be used as potential targets for treating and detecting early CRC. However, since F nucleatum is not universally present in all CRCs and its DNA is only detected in about $13 \%$ of all CRC cases, the use of F. nucleatum-derived proteins as a treatment target should be individualized.

Questions remain on how and when these tumor-related microbial act in the carcinogenesis of CRC species (sequentially, tandemly, or simultaneously). In addition, potential species such as Streptococcus gallolyticus and Enterococcus faecalis should be investigated. We must emphasize that further research to understand how the microbial species' arrivals and departures in intestinal mucosa affect the tumor and its progression as time passes through is desperately needed beyond simply listing which species coexist with CRC.

\section{BENEFICIAL EFFECTS OF PRE/PRO/SYNBIOTICS IN THE TREATMENT OF CRC}

\section{Probiotics}

According to the Food and Agriculture Organization of the United Nations and the World Health Organization, probiotics are defined as "live microorganisms which when administered in adequate amounts confer a health benefit on the host. ${ }^{\text {"53 }}$ Most studies before 2010 focused on the role of probiotics and prebiotics in the prevention of colon cancer. However, recent studies have introduced ways to utilize them even during treatment (Table 1). Probiotics are expected to exert anti-tumor and anti-mutagenic activities during cancer treatment since gut microbiota seems to be implicated in chemotherapy efficacy through various mechanisms, including xenometabolism, immune interactions, and altered community structure. ${ }^{54}$

Using an animal colon cancer model, Heydari et al. ${ }^{55}$ have reported that levels of tumor suppressor miRNAs such as miR26b, miR-18a, APC, and PTEN are increased after 5 months of administration of probiotics (Lactobacillus acidophilus, Bifidobacterium bifidum). At the same time, expression levels of 
Table 1. Probiotic Strains in the Treatment of Colorectal Cancer

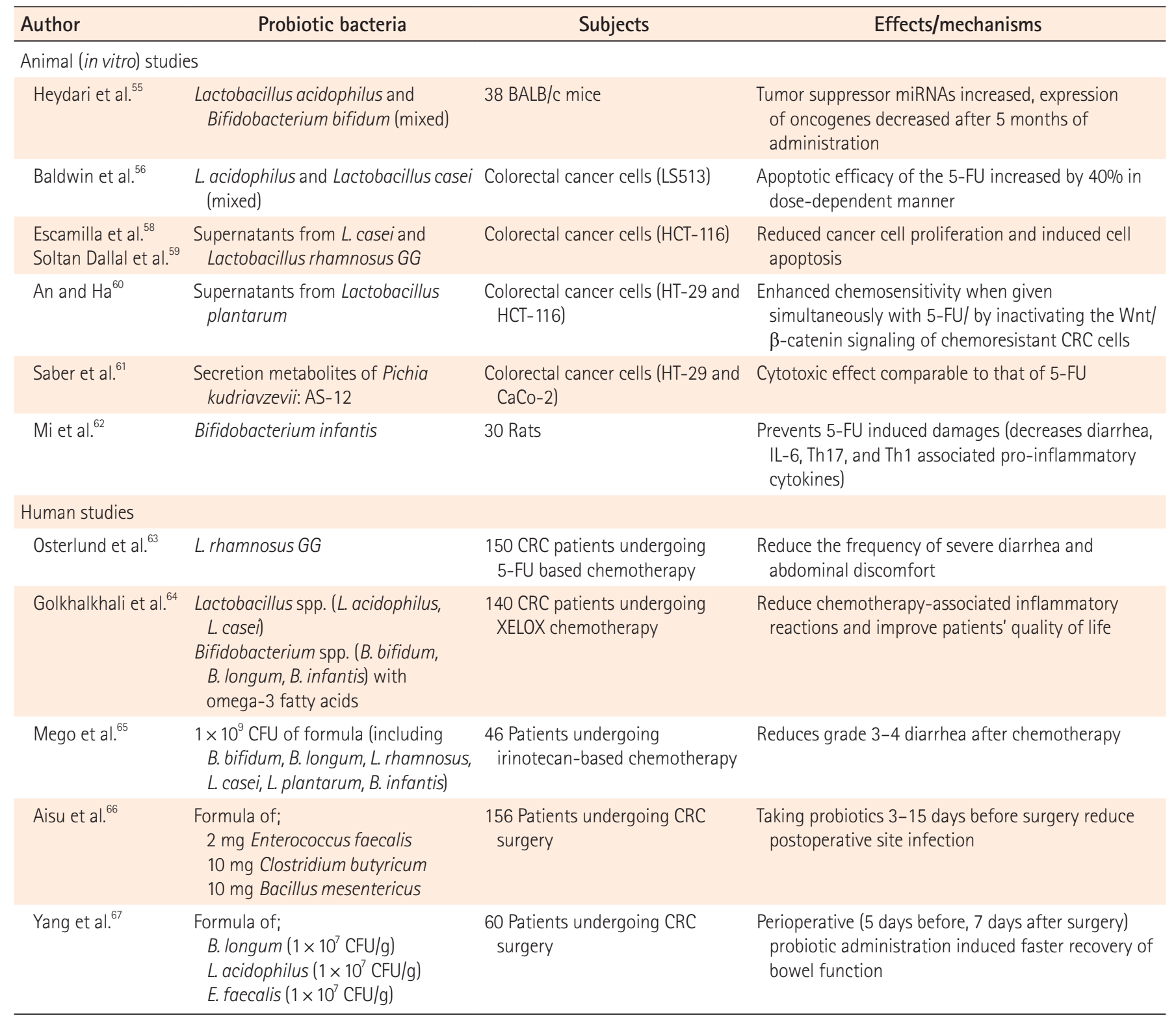

CFU, cell-free supernatants; CRC, colorectal cancer; 5-FU, 5-fluorouracil; XELOX, capecitabine plus oxaliplatin; miRNA, micro RNA; IL, interleukin; Th17, T-helper 17 .

oncogenes such as miR135b and KRAS are decreased. Baldwin et al. ${ }^{56}$ have evaluated the difference in apoptotic activity of 5 -fluorouracil (5-FU) in CRC cell lines using live or inactive lactic acid bacteria (LAB) such as L. acidophilus and Lactobacillus casei at different concentrations. As a result, 5-FU efficacy was observed to increase up to $40 \%$ in a dose-dependent manner with LAB. This was thought to be due to the ability of LAB to convert lactate and acetate to butyrate, a well-known anticarcinogenic agent. ${ }^{57}$

Meanwhile, a study has found that secretory metabolites of LAB also have inhibitory effects on the invasiveness of the hu- man colorectal cell line (HCT-116).$^{58}$ That study was done using extracts of cell-free supernatants of L. casei and Lactobacillus rhamnosus GG (LGG). Soltan Dallal et al. ${ }^{59}$ have compared direct effects on colorectal tumor cells between supernatants of Lactobacillus species and bacterial extracts in terms of proliferation, necrosis, apoptosis, migration, and invasion respectively. As a result, lactobacilli supernatants reduced cancer cell proliferation and induced cell apoptosis without inducing cell necrosis, while lactobacilli extract induced cell necrosis. However, both acted positively on cancer cell migration and invasion. 
In an in vitro study conducted by An and $\mathrm{Ha}^{60}$ with 5-FU resistant colon cancer cell lines (HT-29 and HCT-116), L. plantarum cell-free supernatants enhanced the chemosensitivity when given simultaneously with 5-FU. In addition, various types of Lactobacillus strains and their supernatants were tested against human colon cancer cell lines. Among them, BCRC17010 strain showed the most promising adhesion ability, longer survival in the gastrointestinal tract, and increased lactate dehydrogenase release. ${ }^{68}$ There might be differences in their abilities to act as an adjunctive agent depending on the substrain of Lactobacillus. On the other hand, one in vitro study has indicated that the direct cytotoxic ability of bacterial secretion metabolites could be comparable to that of 5-FU. Saber et al. ${ }^{61}$ have reported that methanolic extract of secreted metabolites of Pichia kudriavzevii AS-12 (MEPK) can increase the expression of pro-apoptotic mediates in HT-29 and CaCo-2 cell lines, suggesting that it has potential as an anticancer agent.

Chemoprotective effect and anti-CRC properties of Bifidobacterium infantis have also been evaluated in a mouse model. ${ }^{62}$ Similar to results of previous studies, chemotherapy-induced health damages were hindered by a strain of probiotics with changes in T-cell immunity profiles such as decreased IL-6, Th17, and Th1 cell-associated cytokines and increased Foxp3+, Tregs, and so on.

There is a safety issue on the use of probiotics in CRC patients. Probiotics are generally well tolerated in healthy subjects, but in patients with damaged intestinal barrier or compromised immunity, such protection may fail and lead to bacterial translocation, systemic infection and antimicrobial resistance. In a systematic review and meta-analysis, the study suggests probiotics use may be beneficial but 5 case reports showed probiotic-related bacteraemia, fungemia. Despite these case reports, current evidence does not suggest an absolute contraindication on probiotic in cancer patients.

\section{Next-Generation Probiotics}

Next-generation probiotics (NGPs) are defined as "live microorganisms identified on the basis of comparative microbiota analysis that, when administered in adequate amounts, confer a health benefit on the host." Apart from traditional probiotics that have long been isolated from fermented foods, NGPs have been recently isolated due to the development of tools that can now identify and modify these commensal bacteria. NGPs such as Bifidobacterium spp., B. fragilis, Akkermansia municiphila, and Faecalibacterium prausnitzii are opening novel therapeutic horizons in CRC treatment. ${ }^{69}$
Some strains of Bifidobacterium species may enhance the efficacy of cancer therapy with immune checkpoint inhibitors (ICI). Especially, B. fragilis may increase the efficacy of ICI therapy ${ }^{70}$ However, be cautious when using $B$. fragilis as enterotoxin-containing $B$. fragilis has been associated with a negative result, leading to paradoxical CRC development. It has been shown that A. municiphila, contributes to a better efficiency of PD-1 based immunotherapy in mouse models. ${ }^{71,72}$ F. prausnit$z i i$ is the one which takes part in butyrate production and may bring beneficial effects on CRC treatment. However, these ICIrelated probiotic studies have limitations in that they have not been conducted in CRC cell lines. With the introduction of NGPs, probiotics are expected to have an endless potential in the treatment of CRC.

\section{Probiotics Can Improve Chemotherapy-Induced Toxicities}

The administration of probiotic strains can reduce side effects of anticancer therapy, especially adverse events after chemotherapy and radiotherapy. This hypothesis has been reinforced by many studies, ${ }^{73}$ showing that microbiome modulation through alimentation or probiotic supplementation could reduce chemotherapy toxicity and other subsequent side effects in mice and humans. Many papers have suggested that microbemediated xenometabolism could be linked to an increase of chemotherapeutic toxicity, leading to a decrease in treatment efficacy. $^{74,75}$

Chemotherapy regimens based on 5-FU is frequently associated with the risk of intestinal mucositis and diarrhea. The most serious case of toxicity associated with death was reported in Japan following 5-FU and sorivudine combined therapy. Besides, intestinal mucositis can be induced by other various chemotherapy agents (Irinotecan, Doxorubicin, etc.). The accumulation of active xenometabolite (SN-38) from Bacteroides and other $\beta$-glucuronidase-producing bacteria is believed to be involved. In a Finnish study, ${ }^{63} 150 \mathrm{CRC}$ patients who received 5-FU based postoperative adjuvant chemotherapy were randomly assigned to receive chemotherapy for 24 weeks with or without LGG supplementation. Patients who received Lactobacillus had less grade ( 3 or 4 ) diarrhea and fewer chemotherapy dose reductions. No influence on chemotherapy tolerability was reported. Probiotics can produce several organic acids and SCFAs that can help maintain a low $\mathrm{pH}$ in the intestinal lumen, one of key factors in protecting intestinal epithelial cells. In a double-blinded, randomized clinical trial of CRC patients undergoing XELOX (capecitabine plus oxaliplatin) 
chemotherapy, the Malaysian research team has reported that mixed probiotics (L. casei, L. acidophilus, L. lactis, B. bifidum, etc.) for 8 weeks can significantly reduce chemotherapy-associated inflammatory reactions with IL-6 reduction and improve patients' quality of life. ${ }^{64}$ The overall safety of the use of probiotics for the prevention and treatment of chemotherapyinduced diarrhea has been verified through a systemic review and meta-analysis. ${ }^{76}$

The efficacy of probiotics can also be found in chemotherapy-induced neutropenic patients. Most infections in these neutropenic patients are caused by endogenous flora. The main route is through intestinal mucosa. A competitive inhibition of bowel colonization between pathogenic microorganisms and probiotics might be a useful prevention tool for these cancer patients. Therefore, several clinical trials have been performed with the postulation that augmentation of colonization resistance by LAB might be an effective and cost-effective way for prevention of opportunistic infection in leukopenic patients. Probiotics composed of Lactobacillus spp. and Bifidobacterium spp. are generally regarded as safe in neutropenic patients. ${ }^{77}$ However, larger randomized clinical studies should be followed.

\section{Perioperative Use of Probiotics}

Probiotics may also effectively protect the intestinal mucosal barrier in CRC patients undergoing surgical procedures. Many clinical studies studied on the effectiveness of perioperative probiotic supplementation in CRC patients. Taking probiotics from 3 to 15 days before surgery reduced post-operational site infection (Aisu et al. ${ }^{66}$ ), promoted recovery to normal gut function (Tan et al. ${ }^{78}$ ), and reduced postoperative diarrhea (Yang et al. $\left.{ }^{67}\right)$. A randomized, double-blind study ${ }^{79}$ has reported that probiotics supplementation can significantly reduce the rate of all major postoperative complications of colorectal surgery (probiotics $28.6 \%$ vs. placebo $48.8 \%, P=0.010$ ). A systemic review and meta-analysis ${ }^{80}$ also concluded that the administration of probiotics peri-operatively can reduce the infection rate by half and the incidence of pneumonia.

\section{Prebiotics}

Prebiotics are selectively fermentable, non-digestible oligosaccharides, or ingredients that can cause alterations in the composition and activity of gut microbiota conferring health benefits. Prebiotics are carbohydrates including fructooligosaccharides (FOS), xylooligosaccharides, galactooligosaccharides (GOS), inulin, and fructans. FOS and GOS have been compoun- ded mainly investigated as prebiotics. These compounds possess many beneficial properties, including stimulating beneficial indigenous gut bacteria, leading to the production of SCFAs, regulating immune response, controlling gene expression in bacterial cells, improving absorption of micronutrients in colon, and modulating xenobiotic-metabolizing enzymes in colon (Table 2). ${ }^{80}$ Prebiotic inulin enriched with oligofructose combined with probiotics LGG and Bifidobacterium lactis can exert an antitumorigenic activity in azoxymethane-induced colon carcinogenesis in rats. A clinical study of preoperative use of prebiotics in CRC patients demonstrated that it improved the abundancy of commensal microbiota and improved serum immunologic indicators as well. ${ }^{81}$ However, there is currently little clinical research on the effectiveness of prebiotics in colon cancer treatment. Bacteroides is suggested to be a relevant bacterial species for further research on the mechanism of prebiotics. It should be emphasized that prebiotics such as $\beta(1-4)$ GOS, lactulose, and FOS produced by transglycosylation of $\beta$-galactosidases or $\beta$-glucosidases are expected to have their role in CRC prevention. ${ }^{82}$

\section{Synbiotics}

Synbiotics refer to food ingredients or dietary supplements combining probiotics and prebiotics in the form of synergism. The administration of synbiotics in CRC seems to be useful probably due to their immunomodulatory properties and their ability to reduce rates of postoperative infections. The administration of a cocktail consisting of oligofructose-maltodextrin (prebiotics) enriched L. acidophilus, B. bifidum, and Bifidobacteria infantum to rats decreased cancer growth, increased mucin secretion, preservation of tight junctions, and inhibition of inflammation. ${ }^{83}$ This cocktail also modulated gut microbiota compositions. Using a recent colon-specific cancer mouse model, it has been found that treatment with synbiotics can suppress dextran sodium sulfate-induced colitis in CDX2PCre; APC+/flox mice, thereby reducing mortality and inhibiting tumorigenesis. ${ }^{84}$ In a clinical study of 37 CRC patients, administering a synbiotic formula (LGG, B. lactis Bb12, inulin) can decrease tumor proliferation and lead to a positive change of the composition of intestinal microbiota. ${ }^{85}$

\section{CONCLUSION}

The role of microbiome in colorectal carcinogenesis is evident and its potential as a treatment target is also promising. In summary, probiotic strains such as B. infantis, LGG, $L$. acidophilus 
Table 2. Prebiotics/Synbiotics in the Treatment of Colorectal Cancer

\begin{tabular}{|c|c|c|c|}
\hline Author & Prebiotics/synbiotics & Subjects & Effects/mechanisms \\
\hline \multicolumn{4}{|l|}{ Animal studies } \\
\hline Kungbee et al. ${ }^{83}$ & $\begin{array}{l}\text { Lactobacillus acidophilus }\left(6.4 \times 10^{11} \mathrm{CFU}\right) \\
\text { Bifidobacterium bifidum }\left(1.9 \times 10^{10} \mathrm{CFU}\right) \\
\text { Bifidobacteria infantum }\left(1.9 \times 10^{10} \mathrm{CFU}\right) \\
\text { Fructo-oligosaccharide and maltodextrin }\end{array}$ & 40 Sprague Dawley rats & $\begin{array}{l}\text { Administration the synbiotic formula reduces } \\
\text { colon cancer development by decreasing } \\
\text { tumor incidence, multiplicity, and volume } \\
\text { via enhanced TLR2 induced epithelial barrier } \\
\text { integrity and suppression of inflammation. }\end{array}$ \\
\hline Saito et al..$^{84}$ & $\begin{array}{l}\text { Lactobacillus casei }\left(1 \times 10^{8} \mathrm{CFU} / \mathrm{mL}\right) \\
\text { Bifidobacterium breve }\left(1 \times 10^{8} \mathrm{CFU} / \mathrm{mL}\right) \\
\beta \text {-Galactosyl-sucrose }(3.75 \mathrm{~g} / \text { body })\end{array}$ & 17 CPC; Apc mice & $\begin{array}{l}\text { Synbiotics suppressed DSS-induced colitis, } \\
\text { inhibited tumorigenesis. Neither probiotics } \\
\text { nor prebiotics alone had any effect on } \\
\text { inflammation and tumorigenesis. }\end{array}$ \\
\hline de Moura et al. ${ }^{86}$ & $\begin{array}{l}\text { L. casei }\left(2.5 \times 10^{10} \mathrm{CFU} / \mathrm{g}\right) \text { with dried extract of } \\
\text { yacon root (rich in FOS) }\end{array}$ & 48 Rats & $\begin{array}{l}\text { Tumor multiplicity was significantly lower in } \\
\text { the group fed synbiotic formulation. }\end{array}$ \\
\hline Gavresea et al. ${ }^{87}$ & $\begin{array}{l}\text { L. acidophilus, Bifidobacterium sp., S. } \\
\text { thermophilus, L. casei, L. delbrueckii, B. longum } \\
\text { (total } 4 \times 10^{8} \text { cells/g) with chicory FOS }\end{array}$ & 60 Rats & $\begin{array}{l}\text { Synbiotics seem to protect against the } \\
\text { appearance of preneoplastic colon lesions in } \\
\text { carcinogen administered rats. }\end{array}$ \\
\hline Li et al. ${ }^{88}$ & $\begin{array}{l}\text { Inulin } \\
\text { Mucin (supplemented by altering water or chow) }\end{array}$ & Rats with tumor inoculation & $\begin{array}{l}\text { Inulin and mucin alter gut microbiota. } \\
\text { Inulin attenuates colon cancer growth. }\end{array}$ \\
\hline Lee et al. ${ }^{89}$ & $\begin{array}{l}\text { L. acidophilus }\left(6 \times 10^{10} \mathrm{CFU} / \mathrm{g}\right) \\
10 \% \text { Djulis (Chenopodium formosanum) }\end{array}$ & 60 Rats & $\begin{array}{l}\text { Synbiotics significantly reduced the numbers of } \\
\text { aberrant crypt foci, and regulated apoptosis- } \\
\text { related proteins. }\end{array}$ \\
\hline \multicolumn{4}{|l|}{ Human studies } \\
\hline Rafter et al..$^{85}$ & $\begin{array}{l}\text { Oligofructose-enriched inulin } \\
\text { Bifidobacterium lactis } \\
\text { Lactobacillus rhamnosus GG }\end{array}$ & $\begin{array}{l}37 \text { CRC patients, } \\
43 \text { polypectomized patients }\end{array}$ & $\begin{array}{l}\text { Synbiotics reduced colorectal proliferation } \\
\text { and induced necrosis in colonic cells. It } \\
\text { also improved epithelial barrier function in } \\
\text { polypectomized patients. }\end{array}$ \\
\hline Xie et al. ${ }^{81}$ & $\begin{array}{l}30 \mathrm{~g} \text { prebiotics; } \\
\text { fructooligosaccharides (25\%) } \\
\text { xylooligosaccharides (25\%) } \\
\text { polydextrose }(25 \%) \\
\text { resistant dextrin }(25 \%)\end{array}$ & $\begin{array}{l}140 \text { Patients undergoing CRC } \\
\text { surgery }\end{array}$ & $\begin{array}{l}\text { Preoperative prebiotics ( } 7 \text { days before surgery) } \\
\text { improved the abundance of commensal } \\
\text { microbiota. } \\
\text { Bacteroides is a relevant bacterial species } \\
\text { for further research on the mechanism of } \\
\text { prebiotics. }\end{array}$ \\
\hline Krebs $^{90}$ & $\begin{array}{l}2.5 \mathrm{~g} \text { of each fibers; } \\
\beta \text {-glucan, inulin, pectin, resistant starch } 10^{11} \\
\text { of each spp.; } \\
\text { Pediococcus pentosaceus } \\
\text { Leuconostoc mesenteroides } \\
\text { Lactobacillus paracasei } \\
\text { Lactobacillus plantarum }\end{array}$ & $\begin{array}{l}54 \text { Patients undergoing } \mathrm{CRC} \\
\text { surgery }\end{array}$ & $\begin{array}{l}\text { Synbiotic group had more LABs on GI mucosa } \\
\text { No difference in postoperative course and } \\
\text { complication. }\end{array}$ \\
\hline
\end{tabular}

CFU, cell-free supernatants; FOS, fructooligosaccharides; CRC, colorectal cancer; TLR2, Toll-like receptor 2; DSS, dextran sodium sulfate; LAB, lactic acid bacteria; Gl, gastrointestinal.

and $L$. casei are expected to play an adjunctive role in the future treatment of CRC through cancer cell immunomodulation and chemoprotective effects. However, before it can be acknowledged as an established anticancer therapy, the following points should be elucidated before modulating intestinal ecosystem in CRC patients: types of probiotic/prebiotic strains we can choose, their optimal concentrations, duration of therapy, and supplementation method (by dietary habit change, oral pills of pro-, pre-, synbiotics) to bring out the best clinical outcomes. In addition, prospective clinical studies revealing how the gut flora and colon cancer interact over time are needed to explore the exact mechanism for their effectiveness.

\section{ADDITIONAL INFORMATION}

\section{Funding Source}

The authors received no financial support for the research, authorship, and/or publication of this article. 


\section{Conflict of Interest}

No potential conflict of interest relevant to this article was reported.

\section{Author Contribution}

Data curation, original draft: Kim SH. Conceptualization, review and editing: Lim YJ. Approval of final manuscript: all authors.

\section{ORCID}

Kim SH

Lim YJ

https://orcid.org/0000-0003-3548-1986

https://orcid.org/0000-0002-3279-332X

\section{REFERENCES}

1. Miller KD, Nogueira L, Mariotto AB, et al. Cancer treatment and survivorship statistics, 2019. CA Cancer J Clin. 2019 Sep; 69:363-385.

2. Siegel RL, Miller KD, Fedewa SA, et al. Colorectal cancer statistics, 2017. CA Cancer J Clin 2017;67:177-193.

3. Miller K. Excellent care for cancer survivors: a guide to fully meet their needs in medical offices and in the community. Santa Barbara: ABC-CLIO, 2012.

4. Sender R, Fuchs S, Milo R. Are we really vastly outnumbered? Revisiting the ratio of bacterial to host cells in humans. Cell 2016;164:337-340.

5. Kau AL, Ahern PP, Griffin NW, Goodman AL, Gordon JI. Human nutrition, the gut microbiome and the immune system. Nature 2011;474:327-336.

6. Nicholson JK, Holmes E, Kinross J, et al. Host-gut microbiota metabolic interactions. Science 2012;336:1262-1267.

7. Wilson ID, Nicholson JK. Gut microbiome interactions with drug metabolism, efficacy, and toxicity. Transl Res 2017;179: 204-222.

8. Barko PC, McMichael MA, Swanson KS, Williams DA. The gastrointestinal microbiome: a review. J Vet Intern Med 2018; 32:9-25.

9. Rescigno M, Urbano M, Valzasina B, et al. Dendritic cells express tight junction proteins and penetrate gut epithelial monolayers to sample bacteria. Nat Immunol 2001;2:361-367.

10. Ostman S, Rask C, Wold AE, Hultkrantz S, Telemo E. Impaired regulatory $\mathrm{T}$ cell function in germ-free mice. Eur J Immunol 2006;36:2336-2346.

11. Sakaguchi S, Yamaguchi T, Nomura T, Ono M. Regulatory T cells and immune tolerance. Cell 2008;133:775-787.

12. Josefowicz SZ, Niec RE, Kim HY, et al. Extrathymically gener- ated regulatory $\mathrm{T}$ cells control mucosal $\mathrm{TH} 2$ inflammation. Nature 2012;482:395-399.

13. Mucida D, Kutchukhidze N, Erazo A, Russo M, Lafaille JJ, Curotto de Lafaille MA. Oral tolerance in the absence of naturally occurring Tregs. J Clin Invest 2005;115:1923-1933.

14. Mazmanian SK, Round JL, Kasper DL. A microbial symbiosis factor prevents intestinal inflammatory disease. Nature 2008; 453:620-625.

15. Round JL, Lee SM, Li J, et al. The Toll-like receptor 2 pathway establishes colonization by a commensal of the human microbiota. Science 2011;332:974-977.

16. Rabizadeh S, Rhee KJ, Wu S, et al. Enterotoxigenic Bacteroides fragilis: a potential instigator of colitis. Inflamm Bowel Dis 2007; 13:1475-1483.

17. Wu S, Rhee KJ, Albesiano E, et al. A human colonic commensal promotes colon tumorigenesis via activation of $\mathrm{T}$ helper type 17 T cell responses. Nat Med 2009;15:1016-1022.

18. Langrish CL, Chen Y, Blumenschein WM, et al. IL-23 drives a pathogenic $\mathrm{T}$ cell population that induces autoimmune inflammation. J Exp Med 2005;201:233-240.

19. Zhang GX, Gran B, Yu S, et al. Induction of experimental autoimmune encephalomyelitis in IL-12 receptor-beta 2-deficient mice: IL-12 responsiveness is not required in the pathogenesis of inflammatory demyelination in the central nervous system. J Immunol 2003;170:2153-2160.

20. Koenen HJ, Smeets RL, Vink PM, van Rijssen E, Boots AM, Joosten I. Human CD25highFoxp3pos regulatory T cells differentiate into IL-17-producing cells. Blood 2008;112:23402352.

21. Osorio F, LeibundGut-Landmann S, Lochner M, et al. DC activated via dectin- 1 convert Treg into IL-17 producers. Eur J Immunol 2008;38:3274-3281.

22. Xu L, Kitani A, Fuss I, Strober W. Cutting edge: regulatory T cells induce CD4+CD25-Foxp3- T cells or are self-induced to become Th17 cells in the absence of exogenous TGF-beta. J Immunol 2007;178:6725-6729.

23. Yang XO, Nurieva R, Martinez GJ, et al. Molecular antagonism and plasticity of regulatory and inflammatory $\mathrm{T}$ cell programs. Immunity 2008;29:44-56.

24. Gaboriau-Routhiau V, Rakotobe S, Lécuyer E, et al. The key role of segmented filamentous bacteria in the coordinated maturation of gut helper T cell responses. Immunity 2009;31: 677-689

25. Wang Y, Yin Y, Chen X, et al. Induction of intestinal Th17 cells by flagellins from segmented filamentous bacteria. Front Immunol 2019;10:2750. 
26. Cummings JH, Pomare EW, Branch WJ, Naylor CP, Macfarlane GT. Short chain fatty acids in human large intestine, portal, hepatic and venous blood. Gut 1987;28:1221-1227.

27. Furusawa Y, Obata Y, Fukuda S, et al. Commensal microbederived butyrate induces the differentiation of colonic regulatory T cells. Nature 2013;504:446-450.

28. McDermott AJ, Huffnagle GB. The microbiome and regulation of mucosal immunity. Immunology 2014;142:24-31.

29. Di Giacinto C, Marinaro M, Sanchez M, Strober W, Boirivant M. Probiotics ameliorate recurrent Th1-mediated murine colitis by inducing IL-10 and IL-10-dependent TGF-beta-bearing regulatory cells. J Immunol 2005;174:3237-3246.

30. Feleszko W, Jaworska J, Rha RD, et al. Probiotic-induced suppression of allergic sensitization and airway inflammation is associated with an increase of $\mathrm{T}$ regulatory-dependent mechanisms in a murine model of asthma. Clin Exp Allergy 2007; 37:498-505.

31. Chen GY. The role of the gut microbiome in colorectal cancer. Clin Colon Rectal Surg 2018;31:192-198.

32. Park CH, Eun CS, Han DS. Intestinal microbiota, chronic inflammation, and colorectal cancer. Intest Res 2018;16:338345 .

33. Gagnière J, Raisch J, Veziant J, et al. Gut microbiota imbalance and colorectal cancer. World J Gastroenterol 2016;22:501-518.

34. Yu LC, Wei SC, Ni YH. Impact of microbiota in colorectal carcinogenesis: lessons from experimental models. Intest Res 2018;16:346-357.

35. Feng Q, Liang S, Jia H, et al. Gut microbiome development along the colorectal adenoma-carcinoma sequence. Nat Commun 2015;6:6528.

36. Arthur JC, Perez-Chanona E, Mühlbauer M, et al. Intestinal inflammation targets cancer-inducing activity of the microbiota. Science 2012;338:120-123.

37. Purcell RV, Pearson J, Aitchison A, Dixon L, Frizelle FA, Keenan JI. Colonization with enterotoxigenic Bacteroides fragilis is associated with early-stage colorectal neoplasia. PLoS One 2017;12:e0171602.

38. Bonnet M, Buc E, Sauvanet P, et al. Colonization of the human gut by E. coli and colorectal cancer risk. Clin Cancer Res 2014; 20:859-867.

39. Raisch J, Buc E, Bonnet M, et al. Colon cancer-associated B2 Escherichia coli colonize gut mucosa and promote cell proliferation. World J Gastroenterol 2014;20:6560-6572.

40. Nougayrède JP, Homburg S, Taieb F, et al. Escherichia coli induces DNA double-strand breaks in eukaryotic cells. Science 2006;313:848-851.
41. Secher T, Samba-Louaka A, Oswald E, Nougayrède JP. Escherichia coli producing colibactin triggers premature and transmissible senescence in mammalian cells. PLoS One 2013;8: e77157.

42. Cougnoux A, Dalmasso G, Martinez R, et al. Bacterial genotoxin colibactin promotes colon tumour growth by inducing a senescence-associated secretory phenotype. Gut 2014;63: 1932-1942.

43. Marchès O, Ledger TN, Boury M, et al. Enteropathogenic and enterohaemorrhagic Escherichia coli deliver a novel effector called Cif, which blocks cell cycle G2/M transition. Mol Microbiol 2003;50:1553-1567.

44. Maddocks OD, Short AJ, Donnenberg MS, Bader S, Harrison DJ. Attaching and effacing Escherichia coli downregulate DNA mismatch repair protein in vitro and are associated with colorectal adenocarcinomas in humans. PLoS One 2009;4:e5517.

45. Nowrouzian FL, Oswald E. Escherichia coli strains with the capacity for long-term persistence in the bowel microbiota carry the potentially genotoxic pks island. Microb Pathog 2012; 53:180-182.

46. Cuevas-Ramos G, Petit CR, Marcq I, Boury M, Oswald E, Nougayrède JP. Escherichia coli induces DNA damage in vivo and triggers genomic instability in mammalian cells. Proc Natl Acad Sci U S A 2010;107:11537-115342.

47. Hussan H, Clinton SK, Roberts K, Bailey MT. Fusobacterium's link to colorectal neoplasia sequenced: a systematic review and future insights. World J Gastroenterol 2017;23:8626-8650.

48. Kostic AD, Chun E, Robertson L, et al. Fusobacterium nucleatum potentiates intestinal tumorigenesis and modulates the tumor-immune microenvironment. Cell Host Microbe 2013; 14:207-215.

49. Bachrach G, Ianculovici C, Naor R, Weiss EI. Fluorescence based measurements of Fusobacterium nucleatum coaggregation and of fusobacterial attachment to mammalian cells. FEMS Microbiol Lett 2005;248:235-240.

50. Gur C, Ibrahim Y, Isaacson B, et al. Binding of the Fap2 protein of Fusobacterium nucleatum to human inhibitory receptor TIGIT protects tumors from immune cell attack. Immunity 2015;42:344-355.

51. Mima K, Nishihara R, Qian ZR, et al. Fusobacterium nucleatum in colorectal carcinoma tissue and patient prognosis. Gut 2016;65:1973-1980.

52. Brennan CA, Garrett WS. Fusobacterium nucleatum: symbiont, opportunist and oncobacterium. Nat Rev Microbiol 2019; 17:156-166.

53. Sánchez B, Delgado S, Blanco-Míguez A, Lourenço A, Guei- 
monde M, Margolles A. Probiotics, gut microbiota, and their influence on host health and disease. Mol Nutr Food Res 2017; 61:1600240.

54. Alexander JL, Wilson ID, Teare J, Marchesi JR, Nicholson JK, Kinross JM. Gut microbiota modulation of chemotherapy efficacy and toxicity. Nat Rev Gastroenterol Hepatol 2017;14: 356-365

55. Heydari Z, Rahaie M, Alizadeh AM, Agah S, Khalighfard S, Bahmani S. Effects of Lactobacillus acidophilus and Bifidobacterium bifidum probiotics on the expression of microRNAs 135b, 26b, 18a and 155, and their involving genes in mice colon cancer. Probiotics Antimicrob Proteins 2019;11:1155-1162.

56. Baldwin C, Millette M, Oth D, Ruiz MT, Luquet FM, Lacroix M. Probiotic Lactobacillus acidophilus and L. casei mix sensitize colorectal tumoral cells to 5-fluorouracil-induced apoptosis. Nutr Cancer 2010;62:371-378.

57. Dos Reis SA, da Conceição LL, Siqueira NP, Rosa DD, da Silva LL, Peluzio MD. Review of the mechanisms of probiotic actions in the prevention of colorectal cancer. Nutr Res 2017;37: 1-19.

58. Escamilla J, Lane MA, Maitin V. Cell-free supernatants from probiotic Lactobacillus casei and Lactobacillus rhamnosus GG decrease colon cancer cell invasion in vitro. Nutr Cancer 2012;64:871-878.

59. Soltan Dallal MM, Mojarrad M, Baghbani F, Raoofian R, Mardaneh J, Salehipour Z. Effects of probiotic Lactobacillus acidophilus and Lactobacillus casei on colorectal tumor cells activity (CaCo-2). Arch Iran Med 2015;18:167-172.

60. An J, Ha EM. Combination therapy of Lactobacillus plantarum supernatant and 5-fluouracil increases chemosensitivity in colorectal cancer cells. J Microbiol Biotechnol 2016;26:14901503.

61. Saber A, Alipour B, Faghfoori Z, Mousavi Jam A, Yari Khosroushahi A. Secretion metabolites of probiotic yeast, Pichia kudriavzevii AS-12, induces apoptosis pathways in human colorectal cancer cell lines. Nutr Res 2017;41:36-46.

62. Mi H, Dong Y, Zhang B, et al. Bifidobacterium infantis ameliorates chemotherapy-induced intestinal mucositis via regulating T cell immunity in colorectal cancer rats. Cell Physiol Biochem 2017;42:2330-2341.

63. Osterlund P, Ruotsalainen T, Korpela R, et al. Lactobacillus supplementation for diarrhoea related to chemotherapy of colorectal cancer: a randomised study. Br J Cancer 2007;97: 1028-1034

64. Golkhalkhali B, Rajandram R, Paliany AS, et al. Strain-specific probiotic (microbial cell preparation) and omega-3 fatty acid in modulating quality of life and inflammatory markers in colorectal cancer patients: a randomized controlled trial. Asia Pac J Clin Oncol 2018;14:179-191.

65. Mego M, Chovanec J, Vochyanova-Andrezalova I, et al. Prevention of irinotecan induced diarrhea by probiotics: a randomized double blind, placebo controlled pilot study. Complement Ther Med 2015;23:356-362.

66. Aisu N, Tanimura S, Yamashita Y, et al. Impact of perioperative probiotic treatment for surgical site infections in patients with colorectal cancer. Exp Ther Med 2015;10:966-972.

67. Yang Y, Xia Y, Chen H, et al. The effect of perioperative probiotics treatment for colorectal cancer: short-term outcomes of a randomized controlled trial. Oncotarget 2016;7:8432-8440.

68. Chen ZY, Hsieh YM, Huang CC, Tsai CC. Inhibitory effects of probiotic Lactobacillus on the growth of human colonic carcinoma cell line HT-29. Molecules 2017;22:107.

69. Martín R, Langella P. Emerging health concepts in the probiotics field: streamlining the definitions. Front Microbiol 2019; 10:1047.

70. Chang CJ, Lin TL, Tsai YL, et al. Next generation probiotics in disease amelioration. J Food Drug Anal 2019;27:615-622.

71. Wang Y, Ma R, Liu F, Lee SA, Zhang L. Modulation of gut microbiota: a novel paradigm of enhancing the efficacy of programmed death-1 and programmed death ligand-1 blockade therapy. Front Immunol 2018;9:374.

72. Cani PD, de Vos WM. Next-generation beneficial microbes: the case of Akkermansia muciniphila. Front Microbiol 2017; 8:1765.

73. Guthrie L, Gupta S, Daily J, Kelly L. Human microbiome signatures of differential colorectal cancer drug metabolism. NPJ Biofilms Microbiomes 2017;3:27.

74. Wallace BD, Wang H, Lane KT, et al. Alleviating cancer drug toxicity by inhibiting a bacterial enzyme. Science 2010;330: 831-835.

75. Wang J, Feng W, Zhang S, et al. Gut microbial modulation in the treatment of chemotherapy-induced diarrhea with Shenzhu Capsule. BMC Complement Altern Med 2019;19:126.

76. Wang YH, Yao N, Wei KK, et al. The efficacy and safety of probiotics for prevention of chemoradiotherapy-induced diarrhea in people with abdominal and pelvic cancer: a systematic review and meta-analysis. Eur J Clin Nutr 2016;70:1246-1253.

77. Serna-Thomé G, Castro-Eguiluz D, Fuchs-Tarlovsky V, et al. Use of functional foods and oral supplements as adjuvants in cancer treatment. Rev Invest Clin 2018;70:136-146.

78. Tan CK, Said S, Rajandram R, Wang Z, Roslani AC, Chin KF. Pre-surgical administration of microbial cell preparation in 
colorectal cancer patients: a randomized controlled trial. World J Surg 2016;40:1985-1992.

79. Kotzampassi K, Stavrou G, Damoraki G, et al. A four-probiotics regimen reduces postoperative complications after colorectal surgery: a randomized, double-blind, placebo-controlled study. World J Surg 2015;39:2776-2783.

80. Liu ZH, Huang MJ, Zhang XW, et al. The effects of perioperative probiotic treatment on serum zonulin concentration and subsequent postoperative infectious complications after colorectal cancer surgery: a double-center and double-blind randomized clinical trial. Am J Clin Nutr 2013;97:117-126.

81. Xie X, He Y, Li H, et al. Effects of prebiotics on immunologic indicators and intestinal microbiota structure in perioperative colorectal cancer patients. Nutrition 2019;61:132-142.

82. Bruno-Barcena JM, Azcarate-Peril MA. Galacto-oligosaccharides and colorectal cancer: feeding our intestinal probiome. J Funct Foods 2015;12:92-108.

83. Kuugbee ED, Shang X, Gamallat Y, et al. Structural change in microbiota by a probiotic cocktail enhances the gut barrier and reduces cancer via TLR2 signaling in a rat model of colon cancer. Dig Dis Sci 2016;61:2908-2920.
84. Saito Y, Hinoi T, Adachi T, et al. Synbiotics suppress colitis-induced tumorigenesis in a colon-specific cancer mouse model. PLoS One 2019;14:e0216393.

85. Rafter J, Bennett M, Caderni G, et al. Dietary synbiotics reduce cancer risk factors in polypectomized and colon cancer patients. Am J Clin Nutr 2007;85:488-496.

86. de Moura NA, Caetano BF, Sivieri K, et al. Protective effects of yacon (Smallanthus sonchifolius) intake on experimental colon carcinogenesis. Food Chem Toxicol 2012;50:2902-2910.

87. Gavresea F, Vagianos C, Korontzi M, et al. Beneficial effect of synbiotics on experimental colon cancer in rats. Turk J Gastroenterol 2018;29:494-501.

88. Li Y, Elmén L, Segota I, et al. Prebiotic-induced anti-tumor immunity attenuates tumor growth. Cell Rep 2020;30:1753-1766.

89. Lee CW, Chen HJ, Chien YH, Hsia SM, Chen JH, Shih CK. Synbiotic combination of djulis (Chenopodium formosanum) and Lactobacillus acidophilus inhibits colon carcinogenesis in rats. Nutrients 2019;12:103.

90. Krebs B. Prebiotic and synbiotic treatment before colorectal surgery: randomised double blind trial. Coll Antropol 2016; 40:35-40. 